\title{
CONTROLE BIOLÓGICO DA MOSCA-DO-MEDITERRÂNEO Ceratitis capitata UTILIZANDO NEMATOIDES ENTOMOPATOGÊNICOS EM LABORATÓRIO
}

\section{BIOLOGICAL CONTROL OF FRUIT FLY Ceratitis capitata USING ENTOMOPATHOGENIC NEMATODES IN LABORATORY}

\author{
Ramon Santos de MINAS ${ }^{1}$ \\ Claudia DOLINSKI ${ }^{2}$ \\ Rômulo da Silva CARVALHO ${ }^{3}$ \\ Ricardo Moreira de SOUZA ${ }^{4}$
}

\begin{abstract}
RESUMO
O presente trabalho avaliou em laboratório, a utilização de diferentes linhagens de nematoides entomopatogênicos (NEPs) individualmente e combinadas visando ao controle biológico da mosca-do-Mediterrâneo, Ceratitis capitata Wied. (Diptera, Tephritidae). No primeiro bioensaio foram utilizadas oito linhagens individualizadas de NEPs (Steinernema carpocapsae NCALL, Heterorhabditis bacteriophora HP88, H. baujardi LPP7, H. indica LPP1, H. indica LPP14, H. sp. LPP9, $H$. sp. LPP17 e H. sp. LPP12) sendo que para cada tratamento foram utilizados 20 tubos de ensaio cada um contendo areia,10 larvas $\mathrm{L} 3$ de $C$. capitata e 100 juvenis infectantes (Jls) diluídos em $1 \mathrm{~cm}^{3}$ de água destilada. No tratamento controle foi adicionado $1 \mathrm{~cm}^{3}$ de água destilada. No segundo bioensaio, foram utilizadas cinco larvas de $C$. capitata e as linhagens de nematoides foram combinadas duas a duas num total de 100 juvenis por repetição ( $50 \mathrm{Jls}$ de cada linhagem) Os bioensaios foram conduzidos a $28{ }^{\circ} \mathrm{C}, 80 \%$ UR e 12 de fotoperíodo. A mortalidade média das larvas foi avaliada pelo teste de Tukey a $1 \%$. Individualmente as linhagens $H$. baujardi LPP7, $H$. indica LPP14, $H$. sp. LPP17 e $H$. sp. LPP12 foram as mais eficientes e causaram mortalidade entre 75 e $98,5 \%$. As combinações mais eficientes foram $H$. indica LPP14 $+H$. sp. LPP9 e $H$. sp. LPP17 + H. sp. LPP12 com mortalidade de larvas L3 de 60 e $82 \%$, respectivamente. Conclui-se que tanto separadamente ou em combinação, algumas linhagens de NEPs podem ser usadas no controle biológico de $C$. capitata, sendo que quando usadas separadamente, a eficiência é maior.

Palavras-chave: mortalidade; juvenis; combinações; biocontrole.
\end{abstract}

\section{ABSTRACT}

The present study investigated under laboratory conditions the use of entomopathogenic nematodes strains separately or in combinations, as biological control agent of Mediterranean fruit fly, Ceratitis capitata Wied. (Diptera, Tephritidae). In the first bioassay, eight strains were used separately (Steinernema carpocapsae NCALL, Heterorhabditis bacteriophora HP88, $H$. baujardi LPP7, $H$. indica LPP1, $H$. indica LPP14, H. sp. LPP9, H. sp. LPP17 e H. sp. LPP12). For each treatment, 20 test tubes with sand, 10 larvae of $C$. capitata and 100 infective juveniles (IJs) diluted in $1 \mathrm{~cm}^{3}$ of distilled water were used. In the treatment control only $1 \mathrm{~cm}^{3}$ of distilled water was added. In the second bioassay it was used the same material; however, the number of $C$. capitata larvae was reduced to five and strains of nematodes combined in pairs, in a total of $100 \mathrm{IJs}$ per replicate (50 individuals of each strain). All treatments were stored in an incubator for 15 days $\left(28^{\circ} \mathrm{C}\right.$, $80 \% \mathrm{RU}$ and $12 \mathrm{~h}$ photoperiod). The average mortality of larvae L3 was evaluated by Tukey test at $1 \%$. The strains $\mathrm{H}$. baujardi LPP7, $H$. indica LPP14, $H$. sp. LPP17 and $H$. sp. LPP12 were the most efficient ones, reaching mortalities range between 75 and $98.5 \%$. In the second experiment, the most effective combinations were $H$. indica LPP14 $H$. sp. LPP9 and $H$. sp. LPP17 $+H$. sp. LPP12 with mortality of 60 and $82 \%$, respectively. We concluded that the use of NEPs in the biological control of $C$. capitata is a feasible alternative either using species separated or in combination, but the first one may reach higher mortality.

Key-words: mortality; juveniles; pairs; biocontrole; Tephritidae

\footnotetext{
${ }^{1}$ Estudante doutorado, CCTA/LEF, Universidade Estadual do Norte Fluminense Darcy Ribeiro, Campos dos Goytacazes, RJ, Brazil. E-mail: ramonminas@bol.com.br

${ }^{2}$ CCTA/LEF, Universidade Estadual do Norte Fluminense Darcy Ribeiro, Campos dos Goytacazes, RJ, Brasil. E-mail: claudia.dolinski@censanet.com.br.

${ }^{3}$ Embrapa Mandioca e Fruticultura, Rua Embrapa, s/nº. Cruz das Almas, BA - Brasil - CEP 44380-000. E-mail: romulo@cnpmf.embrapa.br ${ }^{4}$ CCTA/LEF, Universidade Estadual do Norte Fluminense Darcy Ribeiro, Campos dos Goytacazes, RJ, Brasil. E-mail: ricmsouza@censanet.com.br
} 
MINAS, R.S. et al. Controle biológico da mosca...

\section{INTRODUÇÃO}

Várias pragas atacam as fruteiras e, dentre elas, as moscas-das-frutas (Tephritidae) dos gêneros Anastrepha (Macquart) e Ceratitis (Wied.) são as que causam maiores prejuízos à fruticultura mundial (Malavasi et al., 2000). Uma das espéciespraga mais freqüente e de maior importância econômica para os fruticultores é a mosca-doMediterrâneo, Ceratitis capitata (Wied.), por suas larvas se alimentarem da polpa das frutas, facilitando podridões e queda prematura de frutos infestados. Além dos danos diretos, as moscas-das-frutas causam problemas para a exportação de frutos "in natura" uma vez que os países importadores aplicam rigorosas leis de quarentena exigindo um tratamento eficaz de controle na pré e pós-colheita (Agrianual, 2006).

A utilização indiscriminada de agrotóxicos no controle de moscas-das-frutas provoca desequilíbrios na cadeia alimentar devido à eliminação de inimigos naturais e problemas de segurança alimentar e quarentenária. Tais problemas têm levado a comunidade científica a buscar alternativas ecologicamente apropriadas como a utilização de agentes biológicos visando ao controle desta importante praga da fruticultura. Dentre esses agentes benéficos, os nematoides entomopatogênicos (NEPs) dos gêneros Steinermema e Heterorhabditis (Rhabditida: Steinematidae, Heterorhabditidae), têm demonstrando potencialidade para controle de insetos que possuam pelo menos uma fase do seu ciclo biológico no solo (Molina \& López, 2003), característica essa peculiar às moscas-das-frutas em geral.

Os nematoides no terceiro estádio ou juvenis infectantes (Jls) podem permanecer um determinado tempo no solo a procura de um hospedeiro suscetível. Nematoides nesse estádio não se alimentam nem se desenvolvem, sendo a sobrevivência deles limitada por suas reservas energéticas na forma de glicogênio. Uma vez dentro de um inseto hospedeiro, liberam células da bactéria simbionte que carregam. Estas produzem toxinas que ocasionam a morte do inseto-hospedeiro em 24 a $48 \mathrm{~h}$. As bactérias e os tecidos degradados do insetohospedeiro fornecem nutrientes para o desenvolvimento dos nematoides (duas a três gerações dentro do hospedeiro), que se dá em um período de sete a quatorze dias, dependendo da temperatura, espécie de nematoide e densidade inicial de inóculo (Adams \& Nguyen, 2002). Casos de sucessos têm sido relatados na literatura quanto ao uso de nematoides entomopatogênicos no controle de diversas pragas, dentre elas as moscas das frutas (Stark \& Lacey, 1999; Gazit et al., 2000; Laborda et al., 2003; Toledo et al., 2005). Desta forma o objetivo deste trabaIho foi avaliar o potencial de oito linhagens de nematoides entomopatogênicos, utilizadas separadamente e em combinações, visando ao controle biológico de larvas L3 da mosca-do-Mediterrâneo, C. capitata, em laboratório.

\section{MATERIAL E MÉTODOS}

Os bioensaios foram conduzidos no Laboratório de Entomologia e Fitopatologia da
Universidade Estadual do Norte Fluminense Darcy Ribeiro em Campos dos Goytacazes, RJ, no período de setembro a novembro de 2006. Os nematoides entomopatogênicos utilizados nos experimentos foram multiplicados em larvas de Galleria mellonella L. (Lepidoptera: Pyralidae), segundo procedimento descrito por Woodring \& Kaya (1988). Os Jls que emergiam das larvas mortas foram coletados com uma pipeta de vidro durante 6 dias e acondicionados em garrafas de cultura de células em suspensão aquosa a $16^{\circ} \mathrm{C}$, para posterior utilização nos experimentos.

O bioensaio 1 foi conduzido em delineamento intereiramente casualizado, com oito linhagens de nematoides entomopatogênicos (NEPs) utilizadas individualmente (Steinernema carpocapsae (Weiser) NCALL, Heterorhabditis bacteriophora (Poinar) HP88, $H$. baujardi, Phan, Subbotin, Nguyen \& Moens LPP7, $H$. indica Poinar, Karunakar \& David LPP1, H. indica LPP14, $H$. sp. LPP9, $H$. sp. LPP17 e $H$. sp. LPP12). Foram utilizados para cada linhagem 20 tubos de ensaio ( $3 \mathrm{~cm}$ diâmetro $X 8 \mathrm{~cm}$ altura) contendo $32 \mathrm{~g}$ de areia autoclavada, onde foram adicionados $100 \mathrm{Jls}$ em $1 \mathrm{~cm}^{3}$ de água destilada e dez larvas (L3) de mosca-do -Mediterrâneo. Os tubos foram fechados com filme plástico de PVC, que foi perfurado com uma agulha para facilitar a aeração, e armazenados em câmara climatizada $\left(28{ }^{\circ} \mathrm{C}, 80 \%\right.$ UR, $12 \mathrm{~h}$ fotoperíodo), onde permaneceram por 15 dias, quando então começaram a emergir os adultos provenientes das larvas não infectadas por Jls. O tratamento controle foi estabelecido seguindo os mesmos procedimentos dos demais, exceto pela ausência de nematoides (total de nove tratamentos e 200 repetições/tratamento). Através do programa Infostat / F (Infostat, 2010), foi feita a análise de variância, e a média de mortalidade dos tratamentos comparados pelo teste de Tukey a $1 \%$. O experimento foi repetido logo após a obtenção dos primeiros resultados, seguindo os mesmos parâmetros estabelecidos no primeiro ensaio visando à confirmação destes.

No bioensaio 2, as mesmas linhagens utilizadas anteriormente foram ordenadas em combinações pareadas, baseadas em aspectos biológicos particulares de cada linhagem, tais como facilidade de manuseio e capacidade de infecção. A unidade experimental para cada tratamento foi o tubo de ensaio, contendo $24 \mathrm{~g}$ de areia autoclavada umedecida a $30 \%$, acrescida de 5 larvas L3 de C. capitata e $100 \mathrm{Jls}$ (50 de cada linhagem) nas seguintes combinações: $T 1=S$. carpocapsae NCALL $+H$. bacteriophora HP88; T2 = $H$. baujardi LPP7 $+H$. sp. LPP1; T3= $H$. indica LPP14 + H. sp. LPP9; T4=H. sp. LPP17 $+H$. sp. LPP12. A testemunha teve a mesma composição dos demais tratamentos, exceto pela adição dos Jls (total de cinco tratamentos e 100 repetições/ tratamento). Vinte dias após a avaliação dos dados, o experimento foi repetido de maneira idêntica, visando confirmar a consistência dos resultados primeiramente obtidos. As médias das mortalidades dos tratamentos foram comparadas pelo teste de Tukey a $1 \%$ com o uso do programa Infostat/F (Infostat, 2010), considerando o número de adultos emergidos e contabilizando a mortalidade por 
MINAS, R.S. et al. Controle biológico da mosca...

diferença a partir do número inicial de larvas.

\section{RESULTADOS E DISCUSSÃO}

Larvas L3 de C. capitata foram susceptíveis quando expostas a diferentes linhagens de nematoides isoladamente. Todas as oito linhagens avaliadas foram virulentas e causaram elevados percentuais de mortalidade, que variaram entre $71 \%(H$. bacteriophora HP88) e 98,5\% (H. sp. LPP17). As linhagens Heterorhabditis sp. LPP17 e $\mathrm{H}$. indica
LPP14 foram as mais eficientes no controle de larvas de C. capitata (Tabela 1). Quando os nematoides foram testados em conjunto, houve uma queda no percentual de mortalidade das larvas L3 de $C$. capitata (Tabela 2), quando comparado com a mortalidade causada pelas as mesmas individualmente. A repetição do ensaio mostrou que os experimentos foram conduzidos adequadamente e os resultados foram semelhantes.

TABELA 1 - Mortalidade média de larvas L3 de mosca-do-Mediterrâneo, Ceratitis capitata, quando as linhagens foram adicionadas isoladamente. Média de 200 repetições/tratamento em cada ensaio.

\begin{tabular}{lcc}
\hline \multicolumn{1}{c}{ Tratamentos } & \multicolumn{2}{c}{ Mortalidade \% } \\
\hline & Ensaio 1 & Ensaio 2 \\
\hline Heterorhabditis sp. LPP17 & $98,5 \mathrm{D}$ & $96,5 \mathrm{D}$ \\
H. indica LPP14 & $97,0 \mathrm{D}$ & $95,0 \mathrm{D}$ \\
H. baujardi LPP7 & $85,0 \mathrm{C}$ & $83,0 \mathrm{C}$ \\
Steinernema carpocapsae NCALL & $82,0 \mathrm{BC}$ & $78,5 \mathrm{BC}$ \\
H. sp. LPP12 & $81,0 \mathrm{BC}$ & $77,0 \mathrm{BC}$ \\
H. indica LPP1 & $78,5 \mathrm{BC}$ & $75,5 \mathrm{BC}$ \\
H. sp. LPP9 & $73,0 \mathrm{~B}$ & $72,0 \mathrm{~B}$ \\
H. bacteriophora HP88 & $73,0 \mathrm{~B}$ & $71,0 \mathrm{~B}$ \\
Controle & $13,5 \mathrm{~A}$ & $13,5 \mathrm{~A}$
\end{tabular}

Médias seguidas pela mesma letra na mesma coluna, não se diferenciam estatisticamente pelo teste de Tukey a 1\%. Ensaio 1: $C V=10,31$; $D M S=0,4164$ e Ensaio 2: $C V=9,70 \mathrm{DMS}=0,3970$.

TABELA 2 - Mortalidade média de larvas L3 de mosca do Mediterrâneo, Ceratitis capitata, utilizando combinações de linhagens de nematoides entomopatogênicos.

\begin{tabular}{lcc}
\hline \multicolumn{1}{c}{ Tratamentos } & \multicolumn{2}{c}{ Mortalidade (\%) } \\
\cline { 2 - 3 } & Ensaio 1 & Ensaio 2 \\
\hline Controle & $8,0 \mathrm{~A}$ & $60,0 \mathrm{~A}$ \\
T1 $=$ S. carpocapsae NCALL + H. bacteriophora & $58,0 \mathrm{~B}$ & $60,0 \mathrm{~B}$ \\
HP88 & $64,0 \mathrm{~B}$ & $68,0 \mathrm{BC}$ \\
T2 $=$ H. baujardi LPP7 + H. sp. LPP1 & $68,0 \mathrm{BC}$ & $82,0 \mathrm{C}$ \\
T3 $=$ H. indica LPP14 + H. sp. LPP9 & $80,0 \mathrm{C}$ & \\
T4=H. sp. LPP17 + H. sp. LPP12. & & \\
\hline
\end{tabular}

Médias seguidas pela mesma letra na mesma coluna, não se diferenciam estatisticamente pelo teste de Tukey a 1\%. Ensaio 1: $C V=16.67$, DMS = 0.5164 e Ensaio 2: $C V=16.35$, DMS $=0.4970$

Diferentes pesquisas têm demonstrado o potencial dos NEPs como excelentes agentes de controle de moscas-das-frutas. Lezama et al. (1996), utilizando $4.000 \mathrm{Jls} / \mathrm{cm}^{2}$ de Heterorhabditis sp. por larva de Anastrepha ludens (Loew) observou mortalidade de $82 \%$. Gazit et al. (2000) avaliaram a eficiência do nematóide $S$. riobrave Cabanilhas, Poinar e Raulston Texas contra larvas L3 de C. capitata, utilizando dosagem de $2.000 \mathrm{Jls} / \mathrm{cm}^{2}$ de solo, e obtiveram mortalidade de $90 \%$. Taylor et al. (1998) utilizando S. carpocapsae observaram 50\% de mortalidade utilizando $58 \mathrm{Jls}$ por larva de C. capitata. Lindegren \& Vail (1986) encontraram 50\% de mortalidade utilizando $560 \mathrm{Jls}$ de Heterorhabditis sp. por larva de $C$. capitata. As linhagens utilizadas no presente trabalho apresentaram resultados bas- 
tante expressivos quando comparadas às utilizadas nas demais pesquisas, demonstrando serem bastante eficientes no controle de larvas $L 3$ de $C$. capitata com baixa dosagem $\left(4,2 \mathrm{Jls} / \mathrm{cm}^{2}\right.$ ou $10 \mathrm{Jls}$ por larQuando foi feita a combinação de linhagens foi observada uma queda no percentual de mortalidade de larvas de $C$. capitata oscilando entre $58 \%$ ( $S$. carpocapsae NCALL $+H$. bacteriophora HP88) e $82 \%$ (H. sp. LPP17 + H. sp. LPP12). Koppenhofer et al. (1995) observaram que em infecções de $G$. mellonella, utilizando cada linhagem separadamente, a mortalidade do hospedeiro foi superior aos tratamentos com duas linhagens de nematóides combinadas.

A especificidade e a eficiência de cada isolado de nematóide entomopatogênico sobre um determinado hospedeiro estão diretamente ligadas à sua eficiência na busca, e capacidade de penetração, causar doença e reprodução driblando as resistências naturais do sistema imunológico do inseto. Essa especificidade revela a existência de um processo complexo, cuja compreensão pode esclarecer porque existe tanta variabilidade na eficiência de diferentes linhagens ou mesmo de isolados sobre determinados hospedeiros (Lewis et al., 2006).

Estudando as interações de diferentes linhagens de NEPs em colunas de areia Neumann \& Shields (2006) observaram que em algumas camadas nas colunas, $S$. feltiae (Filipjev) e $H$. bacteriophora foram altamente infectantes, porém quando outras linhagens de NEPs estavam presentes na arena experimental houve inibição na taxa de infecção. Os autores observaram também, não haver infecção múltipla nos insetos hospedeiros. Tais observações demonstram que a concorrência pelo hospedeiro pode inibir a infecção de uma ou mais linhagens. Da mesma forma, no presente trabalho foi observado que linhagens como $H$. baujardi
LPP7, H. indica LPP14, H. sp. LPP17 e H. sp. LPP12 tiveram um destaque maior no primeiro bioensaio quando cada linhagem atuou separadamente, mas não foram da mesma forma eficientes, quando foram combinadas umas com as outras (Tabela 1 e 2).

Ao estudar duas linhagens de gêneros diferentes, Mracek et al. (2005) estabeleceram uma mistura 1:1 dessas linhagens e observaram que apenas uma das espécies desenvolveram até a fase adulta. Tal fato sugere que a competição entre espécies prejudica o desenvolvimento normal das populações em um mesmo hospedeiro, sendo que as habilidades de cada linhagem para se adaptar ao hospedeiro é que determina o seu sucesso. Em contrapartida, algumas espécies preferem hospedeiros mortos, pois não necessitam superar o sistema imunológico do inseto ou estratégias de vedação. Portanto, o que vai determinar o sucesso das populações é o potencial adaptativo de cada uma, e essa variabilidade ocorre em nível de linhagem (San-Blas et al., 2008).

Existe uma infinidade de possibilidades a serem estudadas sobre o comportamento dos nematóides. A sua utilização tanto separadamente como em combinação com outras linhagens deve ser estudada sempre se levando em conta a sua afinidade com o hospedeiro e sua habilidade de infecção, para que possam ser utilizadas com sucesso em programas de controle biológico de insetos-praga.

\section{CONCLUSÕES}

Conclui-se que todas as oito linhagens de NEPs testadas possuem alto potencial para o controle de larvas L3 de C. capitata em laboratório. Contudo, a combinação delas afeta seu poder de infecção.

\section{REFERÊNCIAS}

1. ADAMS, B. J.; NGUYEN, K. B.; Taxonomy and systematic. In: Gaugler, R. (Edit.). Entomopathogenic Nematology. New Jersey: Rutgers University, p. 1-28, 2002.

2. AGRIANUAL. Anuário da Agricultura Brasileira. São Paulo: FNP Consultoria e Comércio, 2006, 521 p.

3. GAZIT, Y.; ROSSLER, Y.; GLAZER, I. Evaluation of entomopathogenic nematodes for the control of Mediterranean fruit fly (Diptera: Tephritidae). Biocontrol Science and Technology, v. 10, n. 2, p. 157-164, 2000.

4. Infostat. Software estatístico. Disponível em: <http://www.infostat.com.ar/>. Acesso em: 01 nov. 2010.

5. KOPPENHÖFER, A. M.; KAYA, H. K.; TAORMINO, S. P. Infectivity of entomopathogenic nematodes (Rhabditida: Steinernematidae) at different soil depths and moistures. Journal of Invertebrate Pathology, v. 65, p. 193-199, 1995.

6. LABORDA, R.; BARGUES, L.; NAVARRO, C.; BARAJAS, O.; ARROYO, M.; GARCIA, E. M., MONTORO, E.; LLOPIS, E.; MARTINEZ, A.; SAYAGUES, J. M. Susceptibility of the Mediterranean fruit fly (Ceratitis capitata) to entomopathogenic nematode Steinernema spp. ("Biorend C"). Bulletin OILB/SROP, v. 26, p. 95-97, 2003.

7. LEWIS, E. E.; CAMPBELL, J.; GRIFFIN, C.; KAYA, H.; PETERS, A. Behavioral ecology of entomopathogenic nematodes. Biological Control, v. 38, n. 1, p. 66-79, 2006.

8. LEZAMA, G. R.; ALATORRE, R. R.; BODAJIL, J. L. F. Virulência de cinco cepas de los hongos entomopatógenos contra Spodoptera frugiperda (Lepidoptera: Noctuidae) en huevos y larvas neonatas. Revista Internacional de Control Biológico, v. 3, n. 1, p.35-39, 1996.

9. LINDEGREN, J. E.; VAIL, P. V. Susceptibility of mediterranean fruit fly, melon fly, and oriental fruit fly (Diptera: Tephritidae) to the entomogenous nematode Steinernema feltiae in laboratory tests. Environmental Entomology, v. 15, n. 3, p. 465468, 1986.

10. MALAVASI, A.; ZUCCHI, R. A.; SUGAYAMA, R. L. Biogeografia. In: MALAVASI, A; ZUCCHI, R. A., (Ed.). Moscas-dasfrutas de importância econômica no Brasil: conhecimento básico e aplicado. Ribeirão Preto: Holos, 2000. p. 93-98.

11. MOLINA J. P.; LÓPEZ N. J. C. Supervivencia y parasitismo de nematodos entomopatógenos para el control de Hypothenemus hampei, (Coleóptera: Scolytidae) en frutos de café. Boletín Sanidad Vegetal de Plagas, v. 29, n. 4, p. 523-533. 2003. 
MINAS, R.S. et al. Controle biológico da mosca...

12. MRÁCEK, Z.; BECVÁR, S.; KINDLMANN, P.; JERSÁKOVÁ, J. Habitat preference for entomopathogenic nematodes, their insect hosts and new faunistic records for the Czech Republic. Biological Control. v. 34, p. 27-37. 2005.

13. NEUMANN, G.; SHIELDS, E. J. Interspecific interactions among three entomopathogenic nematodes, Steinernema carpocapsae, S. feltiae, and Heterorhabditis bacteriophora, with different foraging strategies for hosts in multi-piece sand columns. Environmental Entomology, v. 35, p. 1578-1583, 2006.

14. SAN-BLAS, E.; GOWEN, S. R. Facultative scavenging as a survival strategy of entomopathogenic nematodes. International Journal Parasitology, v. 38, p. 85-91, 2008.

15. STARK, J. E. P.; LACEY, L. A. Susceptibility of western cherry fruit fly (Diptera: Tephritidae) to five species of entomopathogenic nematodes in laboratory studies. Journal of Invertebrate Pathology, v. 74, n. 2, p. 206-208, 1999.

16. TAYLOR, D. B.; SZALANSKI, A. L.; ADAMS, B. J.; PETERSON II, R. D. Susceptibility of house fly (Diptera: Muscidae) larvae to entomopathogenic nematodes (Rhabditidae, Steinernematidae). Biological Control, v.27, n, 6, p. 1514-1519, 1998.

17. TOLEDO, J.; IBARRA, J. E.; LIEDO, P.; GÓMEZ, A.; RASGADO, M. A.; WILLIANS, T. Infection of Anastrepha ludens (Diptera: Tephritidae) larvae by Heterorhabditis bacteriophora (Rhabditida: Heterorhabditidae) under laboratory and field conditions. Biocontrol Science and Technology, v. 15, n, 6, p. 627-634, 2005.

18. Woodring L, Kaya H. K. Steinernematid and Heterorhabditid nematodes: a handbook of techniques. Arkansas Agricultural Experiment Station, Fayetteville, Arkansas. Series Bulletin 331. 30 p, 1988.

Recebido em 07/10/2010

Aceito em 29/03/2011 